\title{
Graphs and maps
}

\section{GRAPHS}

6.1 Exchange value, US dollar vs. euro 93

6.2 Price history, 1 January 1990 to 31 January 1992

6.3 Price history, 1 January 2001 to 26 March $2003 \quad 94$

6.4 Short-term bank claims on developing countries 100

6.5 Decline in short-term bank exposure 100

6.6 'Double-drop' in short-term bank lines 101

11.1 Precipitous shifts 191

11.2 Computer security incidents 196

\section{MAPS}

5.1 A hegemony scenario $\quad 70$

5.2 A multipolar scenario 71

8.1 Ports of CSI 128 